\title{
A UNIVERSIDADE E OS SEUS ESTUDANTES. UM OLHAR DE DENTRO ${ }^{1}$
}

\author{
João Teixeira Lopes
}

\begin{abstract}
RESUMO
Este texto consiste numa reflexão sobre a prática pedagógica universitária a partir de um exercício de sociologia pluriescalar, cruzando múltiplas e complementares escalas de observação: singularidades sociais; sala de aula; instituições; políticas educativas e espaço social. Convocam-se exemplos do quotidiano universitário, mobilizando uma abordagem etnográfica a partir de dentro.
\end{abstract}

\section{PaLAVRas-chave}

Universidade; estudantes; relação pedagógica; Sociologia pluriescalar

\section{Pensar a Universidade A PARTIR do QUOTIDIANo: NOTA INTRODUtória}

Muitas vezes, enquanto universitários, esquecemo-nos de pensar a universidade ou, quando o fazemos, em contextos muito abstratos, abdicamos de retirar consequências desse exercício. Afinal, as rotinas exigem uma reflexividade débil, que se realimenta de previsibilidade, de "compromissos de trabalho" e de procedimentos interacionais que monitorizam e organizam as situações no intuito de reduzir a sua intrínseca complexidade. As reservas comuns de conhecimento sobre o mundo e os implícitos sociais são a base das normas e das suas interpretações, fixando interpretações, encenações e repertórios, como de resto se depreende por uma observação mais atenta dos rituais. Elas são necessárias, mais que necessárias são até fundamentais. Mas, no horror pela desordem, reificam a ordem e o consenso. Além do mais, os múltiplos papéis sociais que somos levados a assumir não comunicam frequentemente entre si, tornando-se um exemplo de colonização do mundo da vida pelo sistema, célebre expressão com que o sociólogo alemão Habermas refere a vitória da razão instrumental sobre o debate organizado, crítico, aberto e racional (Habermas, 2003).

Ora, uma das condições de uma sociologia da Universidade e na Universidade, é não prescindir da complexidade (Pinto, 1994). O que aqui pretendo defender é a ideia de a complexidade partir de um "olhar de dentro". Esse olhar é o início da própria razão sociológica: aproximar-se dos contextos em que ela se constitui como disciplina, método, perspetiva, linguagem, relação. Um olhar sobre os quadros em que se reproduz, sendo que a reprodução, em ciência, não tem de significar mesmidade, antes provoca uma inovação consentida, partilhada, coletiva enquanto reprodução que necessita de micro-revoluções para se manter ativa, construtora, inspiradora, mobilizadora.

'O presente artigo reproduz com várias modificações a Oração de Sapiência proferida pelo autor na FLUP a 13 de novembro de 2014 . 
O olhar de dentro avalia, pois, as comunidades científicas, as condições teóricas e sociais dos modos de fazer ciência, os pontos de vista que criam os objetos, as hierarquias e os capitais que se acumulam num jogo que tem protocolos altamente codificados. Mas esquece-se, tantas vezes, do sociólogo enquanto professor, isto é, enquanto agente de criação de sentidos que se constroem na relação pedagógica, que é uma performance fortemente contextualizada, onde se jogam dimensões intra e extra muros.

Para nada desperdiçar, importa aprofundar a economia do "olhar de dentro", o que exige, para superar a ingenuidade de uma abordagem nativamente espontânea, perscrutar a sala de aula através de um jogo de escalas de observação: macro, meso e microanálise. Em suma, multiplicar os ângulos e as perspetivas, cruzando-os a cada passo.

\section{UMA ESCALA MACRO: ESTADO, POLÍ́TICAS EDUCATIVAS E ESPAÇO SOCIAL}

A uma escala macro, importa perceber que na sala de aula se cruzam processos vários, como os que resultam de quadros de referência fixados por políticas educativas, tantas vezes contraditórias, poucas vezes explícitas, mas onde se insinua e perdura um determinado papel do Estado, uma certa visão da sociedade e do indivíduo, uma razão burocrática, mas também uma hegemonia e uma ideologia, que nunca é homogénea, e onde vivifica ou definha, num feixe de possibilidades e de constrangimentos, a ideia e a concretização de bem comum, de serviço público, de igualdade e de justiça.

A composição da sala de aula, por outro lado, não é imune ao lugar que o ensino superior ocupa num dado projeto nacional, nem tampouco à configuração das desigualdades sociais, pois os estudantes têm uma origem e um percurso onde se mobilizam recursos desiguais.

Será importante, desde logo, perceber, como de resto Firmino da Costa e eu próprio assinalámos num projeto que coordenámos em 2008 (Costa, Lopes \& Caetano, 2014) sob o título "Os Estudantes e os Seus Trajetos no ensino Superior" (ETES), que o ensino superior público, particularmente o universitário, absorveu um crescente número de alunos nas últimas décadas, diversificando públicos e aumentando a eficiência da diplomação (o crescimento do stock de diplomados face ao contingente de matriculados), fenómeno concomitante de um processo de massificação com democratização (sempre incompleta e insuficiente). A taxa bruta de escolarização no ensino superior era, em 2013, de acordo com a, de 53,1\%, enquanto, em 1980, pouco superava os $10 \%$ (Pordata, 2013). Os alunos que encontraremos na sala de aula serão, pois, de meios sociais diversificados, por vezes até contrastantes. Muitos dos seus progenitores terão um nível de escolaridade bem mais reduzido, o que alerta para dinâmicas de aquisição recentes e extrafamiliares de capital cultural. A escolaridade dos jovens que têm hoje 21 anos é três vezes superior à dos seus pais. Encontraremos, pois, variadíssimos casos de estudantes que representam, numa história familiar (e de classe) marcada pela exclusão vincada da instituição escolar, os primeiros exemplos de entrada no outrora sagrado templo do ensino superior. Nada compreenderemos, por exemplo, das chamadas "praxes académicas", se não atendermos também a esta novidade histórica e sociológica. 
Todavia, ter em conta tal "originalidade" na sociedade portuguesa não significa negligenciar os fenómenos de reprodução da estrutura de classes. Se é verdade que uma fatia considerável de jovens com pais pouco escolarizados está ainda a estudar aos 21 anos, não é menos verdade que a maior parte dos indivíduos que está a trabalhar com essa mesma idade provém de famílias desfavorecidas em termos de capital escolar. $\mathrm{Na}$ mesma linha, constata-se que, quanto maior for a escolaridade dos pais, menor é a percentagem de percursos marcados pela reprovação (Faria, 2014). Um estudo recente sobre sucesso, insucesso e abandono na Universidade de Lisboa, coordenado por Almeida (Almeida, 2013), mostra que os jovens oriundos de famílias mais escolarizadas estão sobre representados na população universitária. Mas, comparemos: na década de 60 do século passado, de acordo com os estudos pioneiros de Adérito Sedas Nunes, os estudantes de origens privilegiados tinham 160 vezes mais probabilidades de acederem ao ensino superior (Nunes, 1968); em 1999, uma pesquisa de Ana Nunes de Almeida estimava esse diferencial em vinte vezes; a investigação mais recente coordenada pela mesma socióloga reduzia para três vezes mais o fosso, com uma muito maior seletividade em Medicina, Farmácia e Belas-Artes e uma democratização mais intensa em Letras, Psicologia e Ciências da Educação.

Um debate recente, a propósito de declarações da chanceler alemã, trouxe à tona um consenso que se julgava não existir: todos os intervenientes na polémica recordaram que $25,3 \%$ da população da União Europeia entre os 15 e os 64 anos tinha completado estudos superiores, enquanto a percentagem portuguesa era de $17,6 \%$ e a alemã de $25,1 \%$. Mas caminhará a retórica a par e passo com a política educativa? Números recentes mostram uma desaceleração da taxa de escolarização no ensino superior a partir de 2006, também observável no facto de, em 2009, Portugal estar entre os seis países da EHEA (European Higher Education Area) com perdas de estudantes no ensino superior (Comissão Europeia, 2010).

O projeto ETES, já anteriormente referido, aponta ainda, a partir de uma análise estatística de um vasto manancial de dados sobre os percursos estudantis e o sucesso escolar, que este depende, antes de mais, das caraterísticas das instituições de ensino; do tipo de enino e área de formação; da idade; da organização dos tempos letivos (e dos desiguais graus de investimento no estudo e na frequência das aulas) e ainda da frequência pública do secundário (o que, contrariando os badalados rankings das escolas secundárias, bate genericamente certo com os estudos do serviço de melhoria contínua da UP). Por outras palavras, a seleção social faz-se quer a montante, no decorrer do percurso da escolaridade obrigatória, quer a jusante, pelos processos e lógicas de recrutamento das instituições, em associação com as fileiras de estudo (Martins, 2012).

Devemos olhar para estas tendências sob a dupla face de uma modernidade inacabada (Machado \& Costa, 1998), onde se articulam permanências e roturas. Pela minha parte, dada a aceleração sem precedentes das últimas décadas, coloco a ênfase na intensidade da mudança.

Os estudantes de hoje, na sua pluralidade social e na génese multideterminada (porque multissocializada) do seu capital cultural, desafiam o modelo do "herdeiro". 
A complexidade social, cultural e linguística da sala de aula é hoje uma realidade forte, com o seu potencial de equívocos, desentendimentos e conflitos, mas, apesar de tudo, com o capital de esperança que também representa e que nunca deveremos perder de vista. Desengane-se quem ainda sonha com uma ilusão de homogeneidade.

Atentemos uma vez mais nos dados disponíveis. $23 \%$ dos estudantes de sociologia têm 28 anos ou mais ( $16 \%$ na FLUP). $1 / 3$ aufere uma bolsa dos serviços sociais (27\% na FLUP). 16\% são estudantes-trabalhadores (11\% na FLUP) (Universidade do Porto, Caracterização Socioeconómica dos Estudantes Inscritos na Universidade do Porto, 2012). Sendo escassos (a proveniência de mais de 50\% dos estudantes de sociologia e de letras no que se refere à profissão, nível de escolaridade e condição perante o trabalho dos pais é desconhecida, o que inibe qualquer análise rigorosa - (Universidade do Porto, 2014) (Universidade do Porto, 2012), estes números evidenciam bem a intensidade da heterogeneidade.

\section{UMA ESCALA MESO (1): A SALA DE AULA EXISTE DENTRO DE UMA INSTITUIÇÃo}

Mas importa também aprofundar uma escala meso. Na verdade, a sala de aula não navega no etéreo, antes se incrusta numa instituição com uma matriz organizacional, uma certa missão, uma forma de apresentar, representar e encenar valores, objetivos, padrões de eficiência e otimização de recursos, um organigrama, uma divisão do trabaIho, uma hierarquia que define graus desiguais de poder, de controlo, de centralização de procedimentos e recursos. Não será indiferente, ao mundo que se passa na sala de aula, se essas organizações universitárias possuem mecanismos de integração social e académica, como gabinetes de acompanhamento e aconselhamento, quer psicológico, quer pedagógico, quer ainda profissional; se estruturam momentos de receção aos novos estudantes; se existem guias do estudante, cruciais quando vários estudos colocam a ênfase no $1^{\circ}$ ano como tempo de todas as transições e clímax do abandono (o que se passa igualmente na UP, de acordo com os estudos disponíveis); se estimulam observatórios de diagnóstico e avaliação de processos pedagógicos e de sistemas integrados de qualidade, com produção e análise sistemática de indicadores de ensino e aprendizagem (Veloso Neto, Costa, \& Lopes, 2010) e deteção precoce de variáveis-alteráveis; se promovem boas práticas de apoio social, como bolsas e prémios; se potenciam o trabalho de unidades de inserção na vida ativa; se criam gabinetes de apoio aos estudantes com necessidades especiais; se auscultam e integram opiniões e participações; em suma, se orientam e apoiam:

\footnotetext{
1. O acesso;

2. A integração (social e académica);

3. A permanência com sucesso;

4. A integração profissional.
}

Importa saber, enfim, se estas valências comunicam entre si e se são planeadas tendo em conta as novas missões da universidade (aquilo a que Sousa Santos chama 
a transição de um "conhecimento universitário" para um "conhecimento pluriversitário) ou se, pelo contrário, cedem às lógicas de um comércio de ensino-aprendizagem cada vez mais transnacional, em que "a eficiência, a qualidade e a responsabilização educacional são definidas em termo de mercado" (Santos, 2005, p. 13) e a sociedade da informação e a crescente imaterialização das economias usadas como pretexto para uma omnipresente e omnipotente "metafísica da gestão", unidimensional nos objetivos e processos e ainda na matriz de universidade que pretende instituir. É que existe um abismo entre a "irresponsabilidade social" dos universitários, autárcica e até paroquial, de ouvidos fechados ao canto dos atores sociais e às suas dinâmicas, expetativas e necessidades e as "novas missões" ou epopeias que condenam à irrelevância tudo o que não cabe em critérios pobres de "utilidade", "produtividade" ou "aplicação".

\section{UMA ESCALA MESO (2): OS QUADROS DE INTERAÇÃo NA SALA DE AULA}

É importante, pois, que percebamos como a sala de aula é atravessada quer por políticas educativas, quer por matrizes organizacionais, quer pelas divisões e visões do espaço social (Bourdieu, 2010). Mas é crucial, a um mesmo tempo, que a interação assuma uma relevância própria, enquanto contexto de definição, negociação e construção da realidade, através de trocas comunicacionais que nos relembram, constantemente, quer a partilha de significados, quer os conflitos na sua interpretação. No quadro de interação que é a sala de aula, torna-se relevante detetar as articulações entre as várias escalas de fabricação e observação do social. É certo que os estudantes possuem uma localização no espaço social. Em termos de classe social, encarada de forma multidimensional, na esteira de Weber e Bourdieu, isto é, como apropriação e mobilização desigual de recursos (económicos, sociais, políticos, culturais, simbólicos), mas também um género, uma etnia, uma orientação sexual, eventualmente uma religião... É certo, também, que essas dimensões de localização estrutural se combinam em relações sociais desiguais, que habitam corpos socializados, que por sua vez se exprimem através de convenções mais ou menos ritualizadas, mais ou menos previstas. A encarnação de marcas e propriedades sociais pressupõe, de um modo tenso e concomitante, um processo de subjetivação e singularização (Ferreira, 2008).

\section{UMA ESCALA MICRO: AS SINGULARIDADES INDIVIDUAIS SOCIALMENTE PRODUZIDAS}

À escala microssociológica, podemos observar com minúcia que cada estudante é um exemplo vivo das variações que resultam da combinação entre disposições (para agir, pensar e sentir) e contextos. Em poucas palavras: cada estudante é um sujeito plural num mundo plural. Nele articulam-se, de forma sempre cambiante, processos e princípios múltiplos de socialização, resultados da exposição a uma miríade de agentes de socialização, em contextos assaz diferenciados (família, escola, lazer, bairro, associação, amigos, colegas....) e onde se forjam relações sociais em que ele investe de forma desigual, de acordo com a posição que ocupa na sua ativação, mas também consoante 
o papel social desempenhado e ainda a distância reflexiva face a esse conjunto ou rede de papéis sociais (Lahire, 2013).

Para além de uma origem, os estudantes têm um percurso. Para além de um percurso, um projeto, ainda que diferentemente assumido e muito desigualmente concretizado. Origens, percursos e projetos traduzem-se na sala de aula por mil indícios, ditos e interditos, falas e silêncios.

No citado estudo ETES encontrámos percursos tendenciais ou esperados, no topo e na base, confirmando a predição das origens sociais. Mas descobrimos, igualmente, percursos contratendenciais, ascendentes e descendentes que contrariavam a força de fatalidade da variável matricial. Para além desses, resgatámos percursos focados na educação; percursos com inflexões; percursos com problemas de transição (para a vida adulta, em geral; para o ensino superior, em particular); percursos com problemas de conciliação entre esferas da vida (família, estudos, trabalho...); percursos com dificuldades de integração no ensino superior (académica e social) e, finalmente, percursos com problemas nos modos de estudar.

No fluir de um percurso, cada estudante, além do mais, é um jovem. Em cada um se cruzam desigualdades estruturais, mas também desigualdades de agência. Como jovem, habita mundos da vida (Schütz, 1962) propensos às transições (para a vida adulta, para o trabalho, para a conjugalidade). Tais mundos da vida codificam-se por vezes em sub e até microculturas. Permitirmos que elas sejam matéria-prima da relação pedagógica, depende em muito das nossas orientações normativas e performances pedagógicas.

Quando um grupo de alunas me interpela sobre um eventual excesso de horas letivas, sou levado a perceber que à carga horária diária na Universidade se somam deslocações por vezes penosas, entre uma aldeia longínqua do tão próximo concelho de Penafiel ou os confins da quase vizinha cidade de Santa Maria da Feira, até à metrópole do Porto. Percebo, ainda, que, por serem mulheres, assumem um tremendo peso de tarefas domésticas, a que irmãos e pais se furtam, acrescendo o trabalho próprio da preparação de si (higiene, trabalho corporal demorado, principalmente "quando se tem cabelos longos"), exigentes trabalhos e disciplinas, exercitados antes de aparecer em cena, nessa passerelle que também é a Universidade e onde o corpo se compara (Bourdieu, 2010) e integra, se torna corpo universitário, mas também se subjetiva e singulariza. Compreendo, igualmente, no decorrer da interação, que os recursos económicos são parcos porque as origens sociais são modestas, mas que, apesar do restrito leque de práticas culturais dos progenitores, muitas delas se interessam por fotografia, cinema, música alternativa e escrita literária. Dizem-me, finalmente, que, apesar dos professores lhes lembrarem com afinco que estudantes universitários devem manejar com competência o inglês, a leitura nessa língua se lhes afigura difícil. No entanto, nas várias ocasiões em que tal se propicia, evidenciam um à-vontade intenso no trânsito entre o português e o inglês, quer na passagem de uma frase à outra (alternância de código ou code switching, de acordo com o conceito proposto por vários linguistas norte-americanos (Lahire, 2002), quer mesmo a mistura de línguas numa mesma frase (code mixing), o que acontece sobremaneira quando conversamos sobre a utilização dos novos média e do ciberespaço. 
Hábitos linguísticos heterogéneos (mais do que elas próprias supõem!) e repertórios culturais parcialmente incongruentes, mas decididamente plurais, eis uma hipótese interpretativa que surpreenderia alguma razão sociológica, mas que reenvia para a importância do "estudo dos processos de usar palavras e frases nos contextos de conduta social. A significação não é construída pelo jogo dos significantes, mas pela interseção da produção de significantes com objetos e eventos do mundo, enfocados e organizados pelo agente" (Giddens, 1996, p. 300). Se nem tudo é possível na fabricação da linguagem, se o agente é criativo dentro de uma orquestração "normativamente governada", como diz Chomsky, ainda assim importa não esquecer o que de agência existe na ação social, isto é, de adaptação contextual, de tradução de determinados mundos da vida (Schütz, 1962) para outros, de potencial de metamorfose, na aceção de Gilberto Velho, antropólogo brasileiro, que vai beber o conceito ao poeta latino Ovídio, na tentativa de compreender o trânsito entre realidades distintas, ou províncias de sentido, na aceção da fenomenologia social (Velho, 2003).

Não raras vezes, surpreendo-me com sentidos que desconhecia, associados a certas palavras, que por sua vez remetem para vincadas realidades juvenis. Indago sobre esses inusitados usos e sou levado a percorrer, de longe mas a partir de um olhar próximo, um olhar de dentro, as significações que os próprios estudantes atribuem às suas experiências e trânsitos (sub)culturais. Quando esse diálogo é mais feliz, convido-os a descobrirem dimensões eventualmente menos pensadas ou mesmo impensadas das suas vivências, pois essa é outras das caraterísticas marcantes das práticas sociais: possuem camadas de sentido não imediatamente transparentes aos agentes sociais, ou apenas acessíveis a partir de um esforço acrescido de reflexividade.

Numa unidade curricular que leciono, insto os estudantes a seguirem os passos de Garfinkel, no questionamento experimental das razões práticas e mundanas do senso comum, no afã de construir uma ordem intersubjetivamente partilhada (Garfinkel, 1984) através de normas coletivamente constituídas e constituintes. Quando as "regras" do jogo social são quebradas, nas experiências de rutura, vem à tona o que se pretendia manter implícito e tipificado: a situação de "faculdade", decomposta em expetativas e situações que, por repetição, serão amplamente interiorizadas de forma prática, não reflexiva, como necessidades-disposições. "Experimentem - digo-lhes - sair agora da sala de aula e percorrer os corredores da faculdade à procura de colegas. Quando os encontrarem, metam conversa e perguntem-lhes: “o que fazes aqui? Porque estás aqui?". Registem as respostas e, depois de repetir duas ou três vezes a experiência com interlocutores diferentes, voltem à sala de aula para debater os resultados registados". Ei-los que regressam atónitos: as reações foram de espanto, incredulidade; ou de riso e escárnio; ou ainda de perceção de uma loucura momentânea. Ninguém questiona habitualmente o facto de estarmos aqui e agora. Mas, ao fazê-lo, são as regras da interação social e da definição das situações que surgem em todo o seu esplendor de precaridade.

Outras vezes, é o próprio método sociológico que impõe as ruturas. Desconfiar, desconstruir e encontrar explicações propriamente sociológicas para fenómenos tão correntes como o abuso de consumo de álcool, a violência no namoro e nos afetos ou 
o insucesso e abandono escolares, leva-nos a colocar entre parenteses hipóteses que se julgavam certezas, crenças que valiam por absolutos, representações parciais e contextualizadas, que se erigiam, todavia, numa espécie de passepartout intelectual em jeito de cliché ou mesmo preconceito (relembro sempre nessa altura a frase do filósofo Bachelard: "Terás a idade dos teus preconceitos"). Propaga-se, então, uma atitude de desconfiança metódica face às interpretações espontâneas e tantas vezes epopeicas, como a do livre-arbítrio absoluto ou das diferenças biológicas dos comportamentos de género. $O$ consenso, uma vez mais, é abalado. Mas procuro, por método, escutar as interpretações estudantis, para melhor as contextualizar e desconstruir em conjunto.

\section{E REGRESSO À INSUBSTITUIBILIDADE DA SALA DE AULA COMO INTERAÇÃO DE CO-PRESENÇA}

Não sou apocalíptico nem renuncio às inúmeras vantagens dos novos media, da navegação flutuante no ciberespaço, dos trânsitos entre o real-real e o real-virtual ou da lógica em rede da hiper-realidade. Mas estou fortemente convicto do cariz insubstituível da relação pedagógica face a face em situação de sala de aula, uma vez que só ela condensa o potencial de complexidade das relações sociais contextualizadas. Linguagem verbal e não-verbal, paralinguagem e vaivém entre a situação concreta e a totalidade da experiência social acumulada - eis dos alguns dos recursos possíveis para criar pressupostos de entendimento. Ou para partir do desentendimento como ocasião transformadora em que, no final, cada um dos interlocutores sairá modificado.

A sala de aula é um dos melhores exemplos de que o tempo não é uma essência a-histórica, mas sim um desenrolar de acontecimentos, uma sobreposição de sentidos e contextos, apenas acessíveis analiticamente se multiplicarmos, como aqui pretendi demonstrar, as escalas de observação em direção a uma sociologia que não prescinde das intersecções e cruzamentos. Uma sociologia pluriescalar. Uma sociologia que não se contenta com o "prazer de desiludir" (Bourdieu, 1999) mas que lhe acrescenta, sempre, pelo "olhar de dentro", uma intrínseca dignificação dos agentes sociais.

Há hoje um imenso défice na concretização das melhores expetativas de docentes e alunos. Há sobre todos um peso tremendo de velhas e novas desigualdades sociais. Todavia, há ainda espaço para um significativo trabalho interpessoal a desenvolver por professores e estudantes. Essa margem pode parecer escassa. Mas como duvidar dela? A crença na sua existência é, apesar de tudo, uma boa razão para a Universidade.

\section{REFERÊNCIAS BIBLIOGRÁFICAS}

Almeida, A. N. (2013). Sucesso, insucesso e abandono na Universidade de Lisboa: Cenários e percursos. Lisboa: Educa.

Bourdieu, P. (2010). A distinção. Uma crítica social da faculdade do juízo. Lisboa: Edições 70.

Costa, A. F.; Lopes, J. T. \& Caetano, A. (2014). Percursos de estudantes no ensino superior. Fatores e processos de sucesso e de insucesso. Lisboa: Mundos Sociais. 
Comissão Europeia. (2010). Focus in Higher Education in Europe 2010: The Impact of the Bolonha Process. Brussels: European Comission.

Faria, N. (2014, 27 de fevereiro). Jovens de 21 anos tem três vezes mais escolarização que os pais. Público, p. 5 .

Ferreira, V. S. (2008). Marcas que demarcam. Tatuagem, body piercing e culturas juvenis. Lisboa: Imprensa de Ciências Sociais.

Garfinkel, H. (1984). Studies in ethnomethodology. Cambridge: Polity Press.

Giddens, A. (1996). Estruturalismo, Pós-Estruturalismo e a Produção de Cultura. In A. Giddens \& J. Turner, Teoria Social Hoje (pp. 281-319). São Paulo: Unesp.

Habermas, J. (2003). Mudança estrutural da esfera pública: investigações quanto a uma categoria da sociedade burguesa. Rio de Janeiro: Tempo Brasileiro.

Lahire, B. (2002). Homem plural. Petrópolis: Vozes.

Lahire, B. (2013). Dans les plis singuliers du social. Paris: La Découverte.

Machado, F. L. \& Costa, A. F. (1998). Processos de uma modernidade inacabada. Mudanças sociais e mobilidade social. Em J. Viegas \& A. Costa, Portugal, Que Modernidade? (pp. 14-44). Oeiras: Celta.

Martins, S. D. (2012). Escolas e estudantes na europa. Estruturas, recursos e políticas de educação. Lisboa: Edições Mundos Sociais.

Pinto, J. M. (1994). Propostas para o Ensino das Ciências Sociais. Porto: Afrontamento.

Podata. Base de Dados de Portugal Contemporâneo. (2013). Alunos Matriculados do Ensino Superior. Retirado de www.pordata.pt .

Santos, B. D. (2005). A universidade do século XXI: para uma reforma democrática e emancipatória da universidade. Educação e Sociedade, 23, 137-202.

Schütz, A. (1962). Commonsense and scientific interpretation of human action. The Hague: Martinus Nijhodff.

Universidade do Porto. (2014). Análise do Percurso dos Estudantes Admitidos pelo Regime Geral em Licenciatura $-1^{\circ}$ Ciclo e Mestrado Integrado na Universidade do Porto Em 2008/09, 2009/10, 2010/11. Porto: Universidade do Porto.

Universidade do Porto. (2012). Caracterização Socioeconómica dos Estudantes Inscritos na Universidade do Porto. Porto: Universidade do Porto.

Velho, G. (2003). Projeto e metamorfose: antropologia das sociedades complexas. Rio de Janeiro: Zahar.

Veloso Neto, H., Costa, A. F. \& Lopes, J. T. (2010). Factores, representações e práticas institucionais de promoção do sucesso escolar no ensino superior. Porto: Editorial U.Porto.

\section{NOTA BIOGRÁFICA}

João Teixeira Lopes é Professor Catedrático, Doutorado em Sociologia e Presidente do departamento de Sociologia da FLUP. Tem 25 livros publicados em domínios como a cultura, a juventude, a educação e a emigração. 
E-mail: jmteixeiralopes@gmail.com

Faculdade de Letras da Universidade do Porto, Departamento de Sociologia.

* Submetido: 16-10-2015

* Aceite: 21-10-2015 